\title{
DIFFERENTIAL DISTRIBUTION OF MESSENGER RNAs FOR CATHEPSINS B, L AND S IN ADULT RAT BRAIN: AN IN SITU HYBRIDIZATION STUDY
}

\author{
S. Petanceska, ${ }^{*}$ S. Burke,$\dagger$ S. J. Watson $\dagger$ and L. Devi* $\ddagger$ \\ *Department of Pharmacology, New York University Medical Center, 550 First Avenue, New York, NY \\ 10016, U.S.A. \\ †Mental Health Research Institute, University of Michigan, Ann Arbor, Michigan, U.S.A.
}

\begin{abstract}
The cysteine lysosomal proteases comprise a large family of highly conserved enzymes which are essential for intracellular protein turnover. These proteases are very efficient in their ability to degrade components of the extracellular matrix, and have been implicated in processes of cell growth, malignant transformation and inflammation. There is also a growing body of evidence for their involvement in the metabolism of the amyloid precursor protein. The production of insoluble $\beta \mathrm{A} 4$ amyloid peptide is thought to be one of the key events that lead to the development of Alzheimer's pathology.

To see the physiological role these enzymes play in the brain, we studicd the relative abundance and distribution of the messenger RNAs for three lysosomal cysteine proteases, cathepsins $B$ and $L$ and cathepsin S, by in situ hybridization histochemistry in rat brain. All three enzymes are capable of degrading components of the extracellular matrix but they have different substrate preferences and resistances to neutral $\mathrm{pH}$. We found that the mRNAs for cathepsins $\mathrm{B}, \mathrm{L}$, and $\mathrm{S}$ have different expression patterns in brain. Cathepsin B mRNA shows the highest level of expression. It has a wide distribution, and is preferentially expressed in neurons. The expression patterns of cathepsin B and cathepsin L mRNA overlap in many brain regions; in some areas they complement each other. Cathepsin B and L mRNAs are highly expressed in the choroid plexus, a structure that is instrumental in brain development. Both transcripts are also abundant in the neuropeptide synthesizing hypothalamic nuclei. Cathepsin S mRNA has wide cxpression pattern throughout brain, in grey and white matter. A great number of cells that express cathepsin $\mathrm{S}$ have microglial morphology.

Regions that are known to contain the highest amounts of the amyloid precursor protein express highest levels of cathepsin B and cathepsin L mRNA. Also, all three transcripts are highly represented in regions that are most prone to degeneration in Alzheimer's disease. These results suggest a role for these lysosomal hydrolases released from degenerating cells in the development of Alzheimer's pathology.
\end{abstract}

The mammalian lysosomal cysteine proteases, also known as cathepsins, are members of the papain family of cysteine proteases. It is a large group of enzymes with remarkable homology between species throughout the plant and animal kingdom. ${ }^{50}$ The members of this family are mainly implicated in intracellular protein turnover ${ }^{8,26}$ Due to the ability of these enzymes to degrade constituents of the extracellular matrix, they have also been implicated in processes of cell growth, tumor invasiveness and inflammation. ${ }^{44}$ Although the biochemistry of different members of this family is fairly well studied, their physiological role and the regulatory mechanisms that govern their action in normal and pathological conditions are poorly understood.

Cathepsin B and cathepsin L are two prominent members of the papain family with broad substrate specificity. Their expression is highly elevated in cells that have undergone malignant transformation. ${ }^{36}$ Rat

$\ddagger$ To whom correspondence should be addressed. cathepsin B is coded for by a $2.2 \mathrm{~kb}$ mRNA in the tissues examined.$^{38} \mathrm{It}$ is a multivalent enzyme that can act as dipeptidyl carboxypeptidase and as an endopeptidase; as an endopeptidase it has preference for basic amino acids at the $\mathrm{P} 2$ position. ${ }^{4}$ Cathepsin $B$ is capable of retaining a small but significant percentage of its activity at neutral $\mathrm{pH}^{4}$ Besides tumor invasiveness, cathepsin $\mathrm{B}$ has been implicated in inflammation, and bone resorption. ${ }^{19}$

Cathepsin L, also known as "major excreted protein" is a very potent collagenolytic cysteine lysosomal protease. ${ }^{31}$ It is an endopeptidase of broad specificity with preference for hydrophobic amino acids at the $\mathrm{P} 2$ and $\mathrm{P} 3$ positions. It is quickly inactivated at neutral $\mathrm{pH}^{28}$ In several rat tissues (liver, kidney, testis), there are two transcripts for cathepsin L: a major transcript of about $1.7 \mathrm{~kb}$ and a minor transcript of $2.3 \mathrm{~kb}$, which differ between each other in the lengths of their $3^{\prime}$ untranslated region. ${ }^{20}$ Growth factors, and tumor promoters greatly elevate the levels of cathepsin L mRNA and cause secretion of large amounts of the mature 
enzyme and its precursor form. Its expression is also upregulated during tissue remodeling. 19,25

Recently, we isolated the full-length cDNA for rat cathepsin $S$, as well as partial cDNA for four putative novel cysteine proteases from rat brain. ${ }^{35}$ Rat cathepsin $\mathrm{S}$ is coded for by a $1.4 \mathrm{~kb}$ mRNA. It is an endopeptidase of broad substrate specificity that has preference for small neutral amino acids at the $\mathrm{P} 2$ and $\mathrm{P} 3$ positions. ${ }^{35}$ An intriguing feature of the rat and bovine cathepsin $S$ homologs is their ability to retain up to $80 \%$ of activity at neutral $\mathrm{pH}^{9.10}$ This property makes cathepsin $\mathrm{S}$ a very suitabale candidate for an extracellular as well as an intracellular protease. A human variant, cloned from alveolar macrophages, was shown to have elastinolytic activity, ${ }^{41}$

Little is known about the expression pattern of these three proteases in brain. The expression of cathepsin B has been studied immunohistochemically in rat and human brain. ${ }^{6}$ Little is known about the protein expression of cathepsin $\mathrm{L}$ in rat brain, and there is only one report on the regional distribution of the mRNA for cathepsin $S$ in rat brain. $^{35}$

The cysteine lysosomal proteases have been implicated in the normal and pathogenic metabolism of the amyloid precursor protein. ${ }^{16,17,22,42}$ The processing of amyloid precursor protein, which gives rise to the insoluble $\beta$ A4 amyloid peptide that is found in the core of the mature senile plaques, is one focus in the investigation of the pathogenesis of Alzheimer's disease. There seem to be at least two processing pathways for the amyloid precursor protein. ${ }^{11,16,22,43}$ There is evidence that the nonsecretory pathway of amyloid precursor protein degradation is mediated by cysteine proteases from an acidic intracellular compartment. ${ }^{30}$ When cells that endogenously express high amounts of the precursor protein or have been transfected with the corresponding cDNA are treated with inhibitors of cysteine lysosomal proteases, there is accumulation of a 22,000 mol. wt amyloidogenic C-terminal peptide that is normally assumed to be a short-lived processing intermediate. ${ }^{30}$

High amounts of enzymatically active cathepsin B and $L$ have been detected extracellularly in the senile plaques in the brains of Alzheimer's patients. ${ }^{13.14}$ Degenerating neurons appear to be the main source of these enzymes. Precursor molecules have been found in many of the plaques; therefore, cathepsins may generate the $\beta A 4$ insoluble peptide locally, contributing to the maturation of the plaques.

Because of the strong implications of the involvement of these three proteases in normal and $a b$ normal protein turnover, and tissue remodeling due to growth and trauma, we established a comparative map of the distribution of their mRNAs in rat brain. We examined the relative levels of the mRNAs for cathepsins B, L, and S in rat brain by northern analysis and in situ hybridization histochemistry.

\section{EXPERIMENTAL PROCEDURES}

Northern analysis

Tissue extraction, RNA preparation and northern analysis of total rat brain RNA were performed as previousiy reported ${ }^{33}{ }^{32} \mathrm{P}$-labeled cDNA probes for rat cathepsins $\mathrm{B}, \mathrm{L}$, and $S$ were generated by random priming using as a template $\sim 500 \mathrm{bp}$ fragments of their coding sequences subcloned in the pGEM $3 Z f+$ as reported. ${ }^{35}$ Each probe was hybridized to $30 \mu \mathrm{g}$ of total brain RNA. For quantitative analysis of the results, the blots were reprobed with a random primer labeled cDNA probe against cyclophylin (1B15), a constitutively expressed protein.

The autoradiograms were densitized as described. ${ }^{35}$ Briefly, an image analysis system, consisting of a video camera (Cohu), digitized board (PC vision Plus), and JAVA software (Jandel Scientific) were used. Typically two or three exposures of each membrane were quantified, and the results divided by the exposure time. Only the values which were in the linear range of the film and the camera, as determined by standard curves, were used.

\section{In situ hybridization}

Probe synthesis. The portions of rat cathepsins B, L, and $S$ cDNAs (570, 495 and 502 bp long, respectively) used to produce CDNA probes for the northern analysis were chosen to generate CRNA probes. In this region the homology among the three fragments is as follows: $40 \%$ identity between cathepsin $B$ and $L, 45 \%$ identity between cathepsin $\mathrm{B}$ and $\mathrm{S}$ and $65 \%$ identity between cathepsin $\mathrm{L}$ and $\mathrm{S}$. The fragments were subcloned in the Sma I site of the pGEM $3 Z f+$ vector to enable synthesis of antisense and sense riboprobes from the SP6 or T7 promotor. ${ }^{35} \mathrm{~S}$-labeled cRNA probes with high specific activity were synthesized using standard in vitro transcription protocols. ${ }^{37}$

Tissue preparation and hybridization. Brains were quickly removed from 10-week-old male Sprague-Dawley rats (Taconic, Germantown, NY) and frozen in isopentane at $-30^{\circ} \mathrm{C}$. Fifteen-micrometer-thick coronal sections were mounted on L-polylysine-coated slides and processed for in situ hybridization according to previously published protocols. ${ }^{49}$ Adjacent sections were hybridized with ${ }^{35}$ S-labeled cRNA probes for cathepsins $B, L$, and $S$ of similar specific activities. Hybridization was performed overnight at $50^{\circ} \mathrm{C}$. After eliminating the excess of unbound cRNA probes by treatment with RNase A $(200 \mu \mathrm{g} / \mathrm{ml})$ the sections were washed in $0.1 \times$ standard saline citrate at $65^{\circ} \mathrm{C}$ for $1 \mathrm{~h}$. The tissue was then dehydrated through graded alcohols $(50-100 \%)$, air dried and exposed to Kodak XAR-5 X-ray fim. To enable analysis of the signal on a cellular level, the slides were dipped in NTB-2 or L4 photographic enulsion and stored at $4^{\circ} \mathrm{C}$ for one to three weeks before developing. The developed emulsion dipped sections were counterstained with $0.05 \%$ Cresyl Violet ( $\mathrm{pH} 4.0$ ), and analysed with a Leitz microscope. Ten comparative analyses were performed with sections from all the examined areas using brains from five animals.

In situ hybridization controls. Two types of controls were used to ensure specificity of the hybridization signal: a sense strand control and a RNase A pretreatment control. For the sense strand controls, pairs of adjacent sections were divided in two sets. One set was hybridized to the antisense cRNA probes for cathepsins $B, L$, and $S$, and the other was hybridized to the corresponding sense probes. For the RNase pretreatment control, pairs of adjacent sections were divided in two sets: adjacent sections from the first set were hybridized to antisense radiolabeled cRNA probes for cathepsins $B, L$, and $S$ and processed according to the above protocol. The sections from the second set were treated with RNase A $(200 \mu \mathrm{g} / \mathrm{ml})$ before the proteinase $\mathrm{K}$ treatment, and further processed identically. No signal higher than background was seen with any of the sense probes used, or 
when the tissue was treated with RNase A before hybridization to the antisense probes.

\section{RESULTS}

Northern analysis using rat brain RNA shows that cathepsin B mRNA has the highest level of expression (about two-fold more than cathepsin $S$ and about seven-fold more than cathepsin L mRNA) in rat brain (Fig. 1a). In agreement with previous reports, cathepsin $\mathrm{B}$ and $\mathrm{S}$ are expressed as single transcripts of 2.2 and $1.4 \mathrm{~kb}$, respectively. Two messages were detected for cathepsin L; a major transcript of about $1.7 \mathrm{~kb}$ and a minor transcript of about $2.3 \mathrm{~kb}$ visible upon longer exposure of the blot (Fig. la, lower panel). The minor transcript might correspond to a $2.3-\mathrm{kb}$ transcript found in rat testis, kidney and liver, that was shown to differ from the major transcript in the length of the $3^{\prime}$ untranslated region. ${ }^{20}$

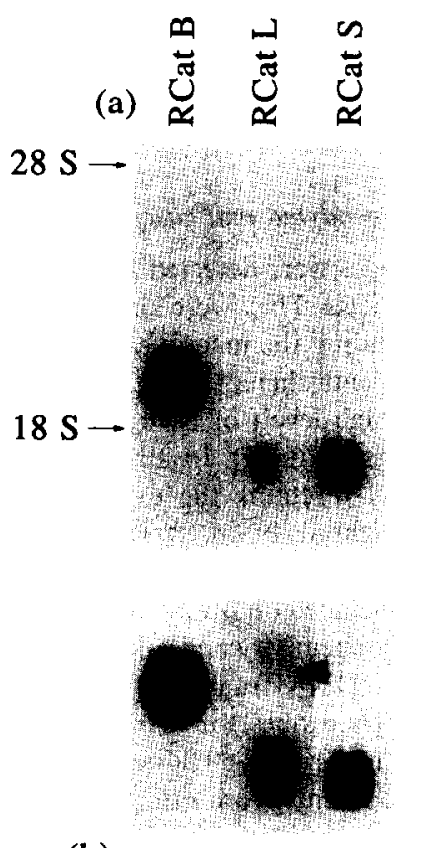

$12 \mathrm{~h}$

$30 \mathrm{~h}$

(b)

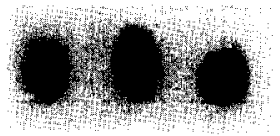

$1 B 15$

Fig. 1. Northern analysis of the relative abundance of cathepsins B, L, and $\mathbf{S}$ in rat brain. (a) Upper panel: approximately $30 \mu \mathrm{g}$ of total RNA was hybridized to radiolabeled rat cathepsin B (RCat B), rat cathepsin L (RCat L), or rat cathepsin $S$ (RCat $S$ ) of similar specific activities. Preparation of RNA, northern blotting, and hybridization conditions are described in Experimental Procedures. The blots were exposed to film for $12 \mathrm{~h}$ at $-70^{\circ} \mathrm{C}$ with an intensifying screen. The positions of the $28 \mathrm{~S}$ and 18S RNA were visualized by ethydium bromide staining. (a) Lower panel: longer $(30 \mathrm{~h})$ exposure of the blots described above shows a minor transcript of $\sim 2.3 \mathrm{~kb}$ for cathepsin L. (b) The same blots were probed with cyclophilin (1B15), a constitutively expressed mRNA.

\section{In situ hybridization}

\section{Telencephalon}

In the olfactory bulbs cathepsins B, L, and $\mathrm{S}$ mRNAs have remarkably different expression patterns (Fig. $2 a-c$ ). Cathepsin B mRNA is most abundant in the mitral cell layer (Fig $2 a, 3 a$ ). It is also expressed in the periglomerular cells of the glomerular layer, as well as in the tufted cells (Fig. 3a). The mRNA for cathepsin L is expressed preferentially in the internal granular cell layer (Fig. 2b). In contrast, the message for cathepsin $S$ is relatively highly expressed in a number of cells from all layers of the olfactory bulbs, including the olfactory nerve layer (Figs 2c, 3h).

In the cortical fields the expression of these messages is different both in terms of quantity and regional distribution. Cathepsin $B$ and $\mathbf{L}$ mRNAs shows highest expression in the frontal, piriform and entorhinal cortex, (Fig. 2d, e,j, k). Cathepsin B mRNA is more abundant both in frontal and entorhinal cortex. Except for layer $I$, cathepsin $B$ and $L$ are expressed in all cortical layers. Cathepsin B mRNA is especially highly expressed in cortical neurons. Cathepsin S mRNA shows a rather homogeneous distribution in all cortical fields and in all cortical laminae. The expression is somewhat higher in the retrosplenial and entorhinal cortex (Fig. 21). From the examination of emulsion dipped sections it seems that this is due to higher expression in individual cells in these areas rather than a greater number of cells expressing this message (not shown). This message also can not be detected in the piriform cortex (Fig. 2f). In the caudate putamen the mRNA for cathepsin $\mathrm{S}$ is observed in a relatively small number of small size cells. There is no significant expression of cathepsin B mRNA in the caudate-putamen, while moderate amounts of cathepsin L mRNA are present in both neurons and glia. Unlike cathepsin L mRNA, cathepsin $\mathrm{S}$ and cathepsin $\mathrm{B}$ transcripts are relatively highly expressed in the ventral pallidum (Fig. 2d, f). The analysis of emulsion dipped sections revealed high levels of cathepsin B and cathepsin L mRNA in the neurons from the nucleus basalis of Meinert (Fig. 3c). The transcripts of cathepsin B and $\mathrm{L}$ are also abundant in the tenia tecta, indusium griseum, neurons from the diagonal band of Broca, the lateral and medial septal nuclei. In the medial septum the expression of cathepsin B mRNA is higher. Cathep$\sin B$ is also highly expressed in the bed nucleus where no significant amounts of cathepsin $L$ or $S$ mRNA could be found. Cathepsins $B$ and $S$ are expressed in high levels in the amygdala.

Cathepsin B mRNA is the most abundant of the three messages in the structures of the hippocampal formation. It is highly expressed in the CAl-3 fields of the Ammon's horn and in the dentate gyrus (Fig. $2 \mathrm{~g}$ ). The message is also abundant in cells from the oriens layer and radiatum layer as well as in the hilus. Cathepsin L mRNA is expressed in the same 
structures to a lesser degree. Also, unlike cathepsin B mRNA its expression in the granular cells of the dentate gyrus overpowers its expression in the pyramidal cells of the CAl-3 fields (Fig. $2 \mathrm{~h}$ ). Cathepsin $S$ mRNA could not be detected in the laminated structures of the hippocampus ( rig. 2i). Again it was detected in small number of diffusely distributed cells of small size. Cathepsin $\mathrm{S}$ transcript is present in glial cells of the corpus callosum (Fig. 2f). High levels of cathepsin L mRNA were observed in a fewer number of cells in this interhemispheric commissure, while the signal for cathepsin B mRNA was no greater than background.

\section{Diencephalon}

The expression of cathepsin B and cathepsin L mRNAs in the hypothalamus is confined to specific nuclei. The messages localize to the ventromedial, dorsomedial, paraventricular, supraoptic, suprachiasmatic and arcuate nucleus. The paraventricular and supraoptic nucleus have the highest levels of both messages (Fig. 3b, $\mathrm{f}$ ). The message for cathcpsin $\mathrm{S}$ could not be detected in significant levels in any of these nuclei.

Cathepsin $S$ mRNA is expressed in a small number of cells in the habenular complex, while cathepsin B and $\mathrm{L}$ are highly expressed in the median habenular body (Fig. $2 \mathrm{~g}-\mathrm{i}$ ). All three messages are widely expressed in different thalamic nuclei; however, cathepsin B mRNA shows the highest and mostly neuronal distribution.

\section{Mesencephalon}

The messages for cathepsin B and L co-localize in the areas of the mesencephalon examined. The areas with highest expression are the nucleus dorsal raphe, the pontine nuclei, the ventral nucleus of the lateral lemniscus, the red nucleus and the substantia nigra pars compacta (Fig. 2j, k). Cathepsin B mRNA is expressed to a greater extent in all these structures, being overwhelmingly abundant in the neurons of the nucleus dorsal raphe, the pontine nuclei, and the red nucleus. Both messages are present in relatively high levels in the central gray (Fig. 2j, k). In the mesencephalic structures cathepsin S mRNA shows again a diffuse distribution pattern with very few exceptions such as central gray and substantia nigra pars reticulata (Figs 21, 3i,j).

The primary sensory neurons and the motor neurons from the mesencephalic and motor nucleus of the trigeminal nerve stand out in the expression of cathepsin B mRNA. The message is also highly expressed in other cranial nerve nuclei (VI, VII). The mRNA for cathepsin $L$ was also observed in these neurons although at lower levels. Relatively high levels of cathepsin $B$ and $L$ were detected in the neurons of the locus coeruleus and different groups of adrenergic neurons in the mesencephalon (not shown).

\section{Cerebellum}

In the cerebellum cathepsin B is most intensely expressed in the Purkinje cells (Fig. 3e). It is also abundant in the granular cell layer (Fig. $2 \mathrm{~m}$ ). The message could be seen in only a few cells in the molecular layer. Cathepsin L mRNA has a similar distribution pattern, but the levels of its expression are drastically lower (Fig. 3g). Neither of these messages was detected in the white matter. Cathepsin $\mathrm{S}$ mRNA is diffusely distributed in the molecular layer, granular layer and white matter of the cerebellum (Fig. 3k).

\section{Choroid plexus, ependyma and vasculature}

All three messages were detected in the ependymal lining of the ventricles. They were also detected in the astrocytes surrounding the macrovessels, and at very low levels in the endothelial lining. In the choroid plexus there are high levels of both cathepsin $B$ and $\mathrm{L}$ transcripts (Figs $2 \mathrm{~g}, \mathrm{~h}, 3 \mathrm{~g}$ ). In all these structures, cathepsin $S$ mRNA retains the expression pattern that it has throughout brain: it is abundant in a relatively small number of cells (Fig. 2i).

Under the stringency conditions used in the in situ hybridization histochemistry and taking into account that none of the cDNA fragments chosen for synthesis of the cRNA probes for in situ hybridization histochemistry is more than $60 \%$ homologous to the corresponding fragments from other known cysteine cathepsins, it is highly likely that we detect specific hybridization signals. However, we cannot exclude

Abbreviations used in Figs 2 and 3

cb cerebellum

cc corpus callosum

cg central gray

cpu caudate-putamen

dr dorsal raphe nucleus

ent entorhinal cortex

e ependymal and subependymal layer

ep ependyma

gcl glomerular cell layer

gl gromerular layer

gr granular layer

ig internal granular layer

igr internal granular layers

$\begin{array}{ll}\text { mes } & \text { mesencephalic trigeminal nucleus } \\ \text { MHb } & \text { median habenular body } \\ \text { mi } & \text { mitral layer } \\ \text { ml } & \text { molecular layer } \\ \text { ms } & \text { medial septum } \\ \text { on } & \text { olfactory nerve layer } \\ \text { pi } & \text { piriform cortex } \\ \text { pvn } & \text { paraventricular nucleus } \\ \text { snr } & \text { substantia nigra reticulata } \\ \text { son } & \text { supraoptic nucleus } \\ \text { vp } & \text { ventral pallidum } \\ \text { wm } & \text { white matter } \\ 3 \mathrm{~V} & \text { third ventricle }\end{array}$




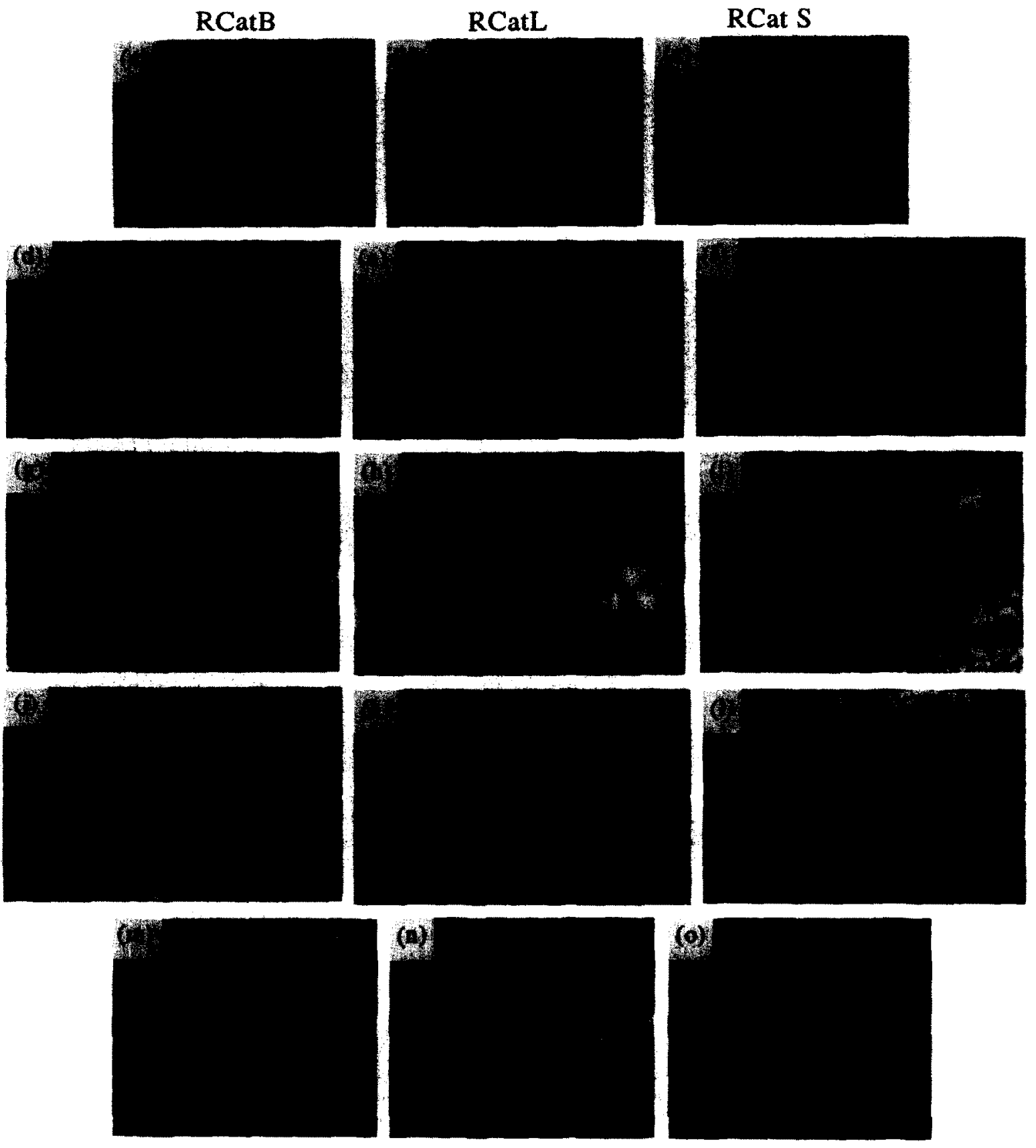

Fig. 2. The comparative distribution of cathepsins B, L, and S by in situ hybridization histochemistry. Darkfield autoradiograms of the distribution of cathepsin B (RCat B; a,d,g,j,m), cathepsin $L$ (RCat $L$; $b, e, h, k, n)$ and cathepsin $S(R C a t S ; c, f, i, l, o)$ mRNAs in coronal sections of rat brain. a,b,c, olfactory bulb; note the abundance of cathepsin B mRNA in the mitral cell layer and its expression pattern complementary to cathepsin L. Also note the presence of cathepsin S mRNA in all layers, including the olfactory nerve layer. (d-f) Frontal cortex and septum; note the pronounced signal for cathepsin $S$ in the corpus callosum and ventral pallidum. (g-i) Hippocampus; note the complementary expression of cathepsin B and $L$ between the $\mathrm{CAl}-3$ fields and dentate gyrus. The arrows in panel I point to lack of cathepsin $S$ signal in the CAl-3 fields and dentate gyrus. $(\mathrm{j}-1)$ mesencephalon; $(\mathrm{m}-0)$ pons and cerebellum; note the high expression of cathepsin $L$ in the choroid plexus of the fourth ventricle and third ventricle. mi, mitral layer; gl, gromerular layer; ig, internal granular layer; on, olfactory nerve layer; cc, corpus callosum; cpu, caudate-putamen; cx, cortex; ms, medial septum; ep, ependyma; vp, ventral pallidum; pi, piriform cortex; $3 \mathrm{v}$, third ventricle; MHb, median habenular body; me5, mesencephalic trigeminal nucleus; $\mathrm{dr}$, dorsal raphe nucleus; ent, entorhinal cortex; $\mathrm{cb}$, cerebellum; $\mathrm{ml}$, molecular layer; $\mathrm{gr}$, granular layer. Exposure times: four days for cathepsin B, 10 days for cathepsin $L$ and seven days for cathepsin $S$. 

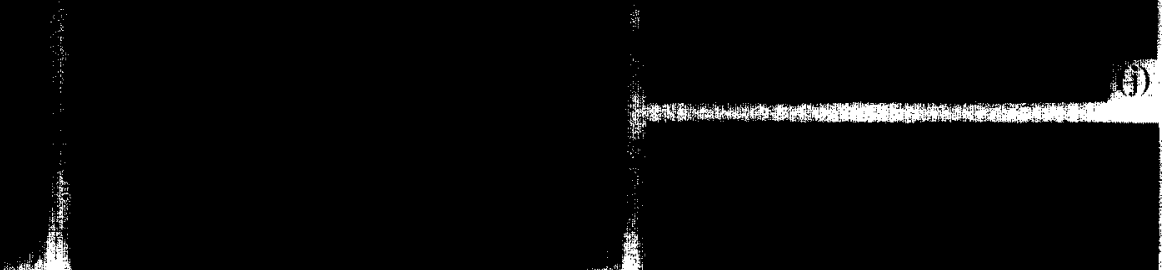

Fig. 3. Darkfield photomicrograph of emulsion-dipped sections showing the expression pattern of cathepsin B mRNA in cells from olfactory bulb (a), paraventricular hypothalamic nucleus (b), nucleus basalis of Meinert (c), mesencephalic trigeminal nucleus (d) and cerebellum (e). Arrowhead in A denotes tufted cells with high expression of cathepsin B mRNA. The expression of cathepsin L mRNA in supraoptic nucleus $(F)$ and in choroid plexus $(G)$. Arrowhead in $F$ points to the astrocytes surrounding blood vessel. Arrows in $G$ denotes purkinje cell layer. The expression of eathepsin $S$ in the olfactory bult (h). substantia nigra reticulata (i), central grey (j) and cerebellum (k). Dashed lines are used to outlinc structures as seen by light microscopy of the same counterstained sections. Exposure times: 10 days for cathepsin B, 21 days for cathepsin $L$ and 15 days for cathepsin S. Magnifications: $20 \times$ for all except $40 \times$ for A.

the possibility that the fragments used as probes cross react with the mRNAs from closely related unknown members of this family.

\section{DISCUSSION}

We examined the relative abundance and regional distribution of the mRN $\mathrm{s}$ for rat cathepsins $\mathrm{B}, \mathrm{L}$, and $S$ in rat brain by northern analysis and by in situ hybridization histochemistry. The results of the northern analysis show that cathepsin B is the most abundant of the three enzymes in rat brain. The detection of two transcripts for cathepsin L is in agreement with the finding by Erickson-Lawrence et al $^{20}$ It is yet to be established whether the brain transcripts also differ only in the length of their $3^{\prime}$ 
untranslated region, and if there is tissue and/or cell-type specificity in their expression. We have also detected similar sized transcripts in rat pheochromocytoma ( $\mathrm{PC1}$ ) and rat glioma ( 6 ) cell lines (unpublished observation). Since we used a segment from the coding sequence of cathepsin $\mathrm{L}$ that recognizes both transcripts as a probe in the in situ hybridization histochemistry, we were not able to distinguish between the distribution of these two messages.

The major finding of our comparative in situ hybridization study is that the mRNAs for cathepsins $B, L$, and $S$ have different expression patterns in rat brain. Cathepsin $B$ and $L$ have wide but not homogeneous distribution. Cathepsin B mRNA is preferentially expressed in neurons, while cathepsin $L$ mRNA is equally expressed in neuronal and nonneuronal cells. The distribution patterns of cathepsin $B$ and cathepsin L mRNAs are largely similar, although there are areas (i.e. olfactory bulbs, hippocampus) where they are significantly different (Fig. 2a, b, g, h). The fact that cathepsin B mRNA is the most abundant of the three proteases, both in terms of wide distribution and levels of message in individual cells, might be due to its ability to function as a dipeptidyl carboxypeptidase and as an endopeptidase. Being such a versatile enzyme it might mark cells with high protein turnover rates.

Among the brain regions examined, cathepsin $L$ mRNA shows the highest expression in the epithelial cells of the choroid plexus (Figs 2h, m, 3g). Iligh levels of cathepsin B transcript are also present in this cerebospinal fluid forming structure (Fig. $2 \mathrm{~g}$, k). Interestingly, the choroid plexus is a major site for the production and secretion of cystatin $\mathrm{C}$, a potent inhibitor of lysosomal cysteine proteases that can inhibit both cathepsin $L$ and cathepsin $B{ }^{3}$ Comparative studies of the expression of cystatin $\mathrm{C}$ have revealed that the peak of its expression occurs early in development. ${ }^{7.47}$ It has also been established that there is a downregulation of its expression in inflammatory pathological conditions. This suggests that the fine equilibrium between the synthesis and secretion of the cysteine proteases and cystatin $\mathrm{C}$ is a part of the processes of normal growth and development as well as part of the acute inflammatory response in brain. It is not known whether cathepsin $B$ and $L$ are normally present in the cerebrospinal fluid. Cathepsin $L$ is readily inactivated at neutral $\mathrm{pH}$, and therefore normally might not cxist in an active circulating form. Nevertheless, in response to different stimuli it can be secreted to act locally in an acidified pericellular environment. ${ }^{19}$

Cathepsin B and cathepsin L are also expressed in the neuropeptide synthesizing nuclei of the hypothalamus: the supraoptic, paraventricular, suprachiasmatic and arcuate nuclei. It is not clear if these enzymes can produce active neuropeptides from inactive precursor molecules. There is evidence, mainly from electron-microscopic studies, that cathepsin B is involved in the production of bioactive molecules from their precursors. ${ }^{32.48}$ Cathepsin B has been found in the secretory vesicles from atrial and juxtaglomerular endocrine cells, and implicated to take part in the maturation of atrial natriuretic factor and renin, respectively. ${ }^{32.48}$ Cathepsin $\mathrm{H}$ is another member of the papain family that is found to co-localize with precursor molecules in secretory granules from corticotrophic and melanotrophic cells from the pituitary and endocrine cells from pancreas. ${ }^{46}$ Also, cathepsins $B, L$, and $S$ have been implicated in the processing of thyroglobulin. ${ }^{35.45}$

Similar levels of cathepsin S mRNA were observed throughout the brain regions examined in gray and white matter. Its overall expression pattern, in a relatively small number of cells scattered throughout brain resembles the distribution of microglia. ${ }^{33}$ Many of the cells that express cathepsin $S$ have size and morphology typical for microglia. Also, microglia play the role of macrophages in brain and cathepsin $\mathrm{S}$ is known to be highly expressed in alveolar macrophages and in spleen ${ }^{29,41}$ Recently, the presence of cathepsins $B$ and $L$ activities were reported in cultured microglia by enzyme histochemistry. ${ }^{2}$ Since cathepsin $\mathrm{S}$ is also capable of cleaving the substrates used in this study, some of the detected activity could be due to its presence in this cell type. Because of its unusual homogeneous pattern of expression cathepsin B might be associated with a particular functional state of different cells, rather than being involved in the general protein turnover and therefore being expressed in most cells from a particular structure.

This study shows a significant correlation between the distribution of cathepsins $B, L$, and S mRNAs and the distribution of the mRNA and protein for different isoforms of the amyloid precursor protein as reported by several other investigators. ${ }^{12.27,34}$ Namely, evidence from immunohistochemistry and in situ hybridization histochemistry studies in rat and mouse brain shows that the highest levels of amyloid precursor protein transcripts and protein are in the mitral cells in the olfactory bulb, cerebral cortical neurons, neurons in the septum and the diagonal band of Broca, the pyramidal and granular cells in the hippocampus, neurons of the amygdala, the red nucleus, the cranial nerve nuclei, pontine nuclei and the Purkinje cells in the cerebellum. ${ }^{12.27 .34 .40}$ The distribution of the amyloid precursor protein in rat brain matches for the most part its distribution in human brain. ${ }^{1.15 .24 .27}$ All these regions contain exceptionally high levels of cathepsin B mRNA and significant levels of cathepsin L mRNA (Figs $2 \mathrm{~g}, \mathrm{~h}, 3 \mathrm{a}, \mathrm{d}$ ). The structures of the basal forebrain, known to be prone to degeneration and dense plaque formation express significant levels of the transcripts for all three enzymes. Like the amyloid precursor protein transcripts, relatively low levels of cathepsins $B, L$, and S mRNA could be detected in the astrocytes surrounding the bigger blood vessels and very low expression was seen in the endothelial lining of the vessels. ${ }^{22.34}$ 
The metabolism of the amyloid precursor protein is a complex and unresolved phenomenon. Recent evidence shows that soluble $\beta$ A4 is a product of normal processing of amyloid precursor protein and that the production of $\beta \mathrm{A4}$ is affected by lysosomotropic agents but not by cysteine protease inhibitors. ${ }^{39,42}$ Therefore, the insolubility of the $\beta \mathrm{A} 4 \mathrm{might}$ be a result of its excessive production and/or defect in its clearence. Nevertheless, the high degree of co-localization of this molecule with cathepsin B and $L$ throughout brain and the evidence by other groups about the involvement of the lysosomal cysteine proteases in the processing of amyloid precursor protein, suggest a role for these enzymes in its processing.

Since high levels of expression of the amyloid precursor protein per se are not sufficient for plaque formation, it is interesting to speculate that deregulation of one or several enzymes involved in its normal processing or ectopic expression of enzymes that are not normally involved in the processing may result in change of the processing pattern of the amyloid precursor protein in terms of excessive production of the $\beta \mathrm{A} 4$ peptide or generation of fragments that have toxic effect on the neighboring neurons. This can elicit a vicious physiological circle where the dying neurons and activated astrocytes and microglia can then further release cathepsins that can generate more amyloid peptides from the native amyloid precursor protein molecules. In this respect the possible preferential expression of cathepsin $\mathrm{S}$ mRNA by microglia is particularly intriguing. Microglia are thought to contribute to the Alzheimer"s pathology as mediators of the inflammatory response in brain. ${ }^{21}$ Although the microglia have been found in the center of mature senile plaques and have been shown to produce different isoforms of the amyloid precursor protein in vitro, their role as a source of plaque amyloid is uncertain..$^{21,23}$ Microglia activated as a result of different trauma might secrete cathepsin $\mathrm{S}$ in the extracellular matrix where it can act on amyloid precursor protein molecules released from damaged neurons. The preference for neutral amino acids at the $\mathrm{P} 2$ and $\mathrm{P} 3$ positions and its resistance to neutral $\mathrm{pH}$, make cathepsin $\mathrm{S}$ an ideal protease for the production of $\beta \mathrm{A} 4$ peptide from the amyloid precursor protein extracellularly. Alternatively, cathepsin $S$ could act intracellularly on endogenous amyloid precursor protein molecules or those produced by damaged neurons and phagocytosed by microglia.

\section{CONCLUSIONS}

We have shown that Cathepsin $B$ and $L$ are widely but differentially expressed. Their distribution patterns overlap to a great extent, but there are areas where they are quite different. Cathepsin S mRNA shows an unusual distribution pattern, being expressed in a relatively small number of different cells in all the regions examined. There is a high degree of correlation between the distribution of cathepsins $B$ \& L mRNAs and the expression of the amyloid precursor protein reported by others. ${ }^{12,27,34,40}$ Also, the morphology and the distribution of many cells that express cathepsin S mRNA is typical for microglia, cells that mediate the inflammatory response and take an active part in the establishment of the cytopathological features of Alzheimer's disease.

Acknowledgements - This work was supported by grants NS-26880 to L.D and MH-42251 \& DA-02265 to S.J.W. We thank Peter Canoll for stimulating discussions and critical reading of the manuscript.

\section{REFERENCES}

1. Bahmanyar S., Higgins G. A., Goldgaber D, Lewis D. A., Morrison J. H., Wilson M. C., Shankar S. K. and Gajdusek S. C. (1987) Localization of amyloid $\beta$ protein messenger RNA in brains from patients with Alzheimer's disease. Science 237, $77-80$.

2. Banati R. B., Gehrmann J., Schubert P. and Kreutzberg G. W. (1993) Cytotoxicity of microglia. Glia 7, $111-118$.

3. Barrett A. J., Davies M. and Grubb A. (1984) The place of human gamma-trace (cystatin C) amongst the cysteine protease inhibitors. Biochem. biophys. Res. Commun. 120, 631-636.

4. Barrett A. J. and Kirshke H. (1981) Cathepsin B, cathepsin H, and cathepsin L. Meth. Enzymol. 80, 535-542.

5. Benowitz L. I., Rodriguez W., Paskevich P., Mufson E. J., Schenk D. and Neve R. L. (1989) The amyloid precursor protein is concentrated in neuronal lysosomes in normal and Alzheimer disease subjects. Expl. Neurol. 106, $237-250$.

6. Bernstein H., Sormunen R., Jarvinen M., Kloss P., Kirschke H. and Rinne A. (1989) Cathepsin B immunoreactive neurons in rat brain. J. Hirnforsch. 30, 313-317.

7. Bollengier F. (1987) Cystatin C, alias post-gamma globulin: a marker for multiple sclerosis? J. clim. Chem. clin. Biochem. 25, 589-593.

8. Bond J. S. and Butler P. E. (1987) Intracellular proteases. A. Rev. Biochem. 56, 333-364.

9. Bromme D., Bonneau P. R., Lachance P., Wiederanders B., Kirschke H., Peter C., Thomas D. Y., Storer A. C. and Vernet T. (1993) Functional Expression of human cathepsin $S$ in $S$. cerevisiae. J. biol. Chem. 268, 4832-4838.

10. Bromme D., Steinert A., Friebe S., Fittkau S., Wiederanders B. and Kirschke H. (1989) The specificity of bovine spleen cathepsin S. Biochem. J. 264, 475-481.

11. Caporaso G. L., Gandy S. E., Buxbaum J. D. and Greengard P. (1992) Chloroquine inhibits intracellular degradation but not secretion of Alzheimer B/A4 amyloid precursor protein. Proc. natn. Acad. Sci. U.S.A. 89, $2252-2256$.

12. Card J. P., Meade R. P. and Davis L. G. (1988) Immunocytochemical localization of the precursor protein for $\beta$-amyloid in the rat central nervous system. Neuron $1,835-846$.

13. Cataldo A. M. and Nixon R. A. (1990) Enzymatically active lysosomal proteases are associated with amyloid deposits in Alzheimer brain. Proc. natn. Acad. Sci. U.S.A. 87, 3861-3865. 
14. Cataldo A. M., Paskevich P. A., Kominami E. and Nixon R. A. (1991) Lysosomal hydrolases of different classes are abnormally distributed in brains of patients with Alzheimer disease. Proc. natn. Acad. Sci. U.S.A. 88, 10,998-11,002.

15. Cohen M. L., Golde T. E., Usiak M. F., Younkin L. H. and Younkin S. G. (1988) In situ hybridization of nucleus basalis neurons show increase $\beta$-amyloid mRNA in Alzheimer disease. Proc. natn. Acad. Sci. U.S.A. 85, $1227-1231$.

16. Cole G. M., Huynh T. V. and Saitoh T. (1990) Evidence for lysosomal processing of amyloid $\beta$-protein in culture cells. Neurochem. Res. 14, 933-939.

17. Cole G. M., Masliah E., Sheiton E. R., Chan H. W., Robert R. D. and Saitoh T. (1991) Accumulation of amyloid precursor fragment in Alzheimer's plaques. Neurobiol. Aging 12, 85-88.

18. Dickson D. W., Lee S. C., Mattiace L. A., Yen S.-H. C. and Brosnan C. (1994) Microglia and cytokines in neurological disease with special reference to AIDS and Alzheimer's disease. Glia (in press).

19. Eitherington D. J., Pugh D. and Silver I. A. (1981) Collagen degradation in an experimental inflammatory lesion: studies on the role of the macrophage. Acta. biol. med. germ. 40, 1625-1636.

20. Erickson-Lawrence M., Zabludoff S. D. and Wright W. W. (1991) Cyclic protein-2, a secretory product of rat sertoli cells, is the proenzyme form of cathepsin L. Molec. Endocr. 5, 1789-1798.

21. Haass C., Hung A. Y. and Selkoe D. J. (1991) Processing of beta-amyloid precursor protein in microglia and astrocytes favours an internal localization over constitutive secretion. J. Neurosci. 11, 3783-3793.

22. Haas C., Koo E. H., Mellon A., Hung A. Y. and Selkoe D. J. (1992) Targetting of cell-surface $\beta$-amyloid precursor protein to lysosomes: alternative processing into amyloid-bearing fragments. Nature $357,500-502$.

23. Haga S., Akai K. and Ishii T. (1989) Demonstration of microglial cells in and around senile plaques in the Alzheimer brain. Acta neuropath. 77, 569-575.

24. Higgins G. A., Lewis D. A., Bahmanyar S., Goldgaber D., Gajdusek D. C., Young W. G., Morrison J. H. and Wilson M. C. (1988) Differential regulation of amyloid- $\beta$-protein mRNA expression within hippocampal neuronal subpopulations in Alzheimer's disease. Proc. natn. Acad. Sci. U.S.A. 85, 1297-1301.

25. Jaffe R. C., Donnelly K. M., Mavrogianis P. A. and Verhage H. G. (1989) Molecular cloning and characterization of a progesterone-dependent cat endometrial secretory protein complementary deoxyribonucleic acid. Molec. Endocr. $3,1807-1814$.

26. Katunuma N. and Kominami E. (1983) Structures and functions of lysosomal thiol proteinases and their endogenous inhibitors. Cur. Top. cell. Regul. 22, 71-101.

27. Kawareabayashi T., Shoji M., Harigaya Y., Yamaguchi H. and Hirai S. (1991) Amyloid beta/A4 protein precursor is widely distributed in both the central and peripheral nervous system of the mouse. Brain Res. 552, 1-7.

28. Kirschke H., Schmidt I. and Wiederanders B. (1986) Cathepsin S: a cysteine protease from bovine lymphoid tissue is distinct from cathepsin L. Biochem. J. 240, 455-459.

29. Kirschke H., Wieeranders B., Bromme D. and Rinne A. (1989) Cathepsin S from bovine spleen. Biochem. J. 264, 467-473.

30. Knops J., Lieberburg I. and Sinha S. (1992) Evidence for a non-neurosecretory acidic degradation pathway for amyloid precursor protein in 293 cells. J. biol. Chem. 267, 16,022-16,024.

31. Mason R. W., Gal S. and Gottesman M. M. (1987) The identification of the major excreted protein (MEP) from a transformed mouse fibroblast cell line as a catalytically active precursor form of cathepsin L. Biochem. J. 248, 449-454.

32. Matsuba H., Watanabe T., Watanabe M., Ishii Y., Waguri S., Kominami E. and Uchiyama Y. (1989) Immunocytochemical localization of prorenin, renin, and cathepsins B, H, and L injuxtaglomerular cells of rat kidney. J. Histochem. Cytochem. 37, 1689-1697.

33. Milligan C. E., Cunningham T. J. and Levitt P. (1991) Differential immunochemical markers reveal the normal distribution of brain macrophages and microglia in the developing rat brain. J. comp. Neurol. 314, $125-135$.

34. Mita S., Schon E. and Herbert J. (1989) Widespread expression of amyloid beta-protein precursor gene in rat brain. Am. J. Path. 134, 1253-1261.

35. Petanceska S. and Devi L. (1992) Sequence analysis, tissue distribution and expression of rat cathepsin S. J. biol. Chem. 267, 26,038-26,043.

36. Qian F., Bajkowski A., Steiner D. F., Chan S. J. and Frankfater A. (1989) Expression of five cathepsins in murine melanomas of varying metastatic potential and normal tissues. Cancer Res. 49, 4870-4875.

37. Sambrook J., Fritsch E. F. and Maniatis T. (1989) Molecular Cloning. CSH Laboratory Press. Cold Spring Harbor.

38. San Segundo B., Jin Chan S. and Steiner D. F. (1985) Identification of cDNA clones encoding a precursor of rat liver cathepsin B. Proc. natn. Acad. Sci. U.S.A. 82, 2320-2324.

39. Seubert P., Vigo-Pelfrey C., Fsch F., Lee M., Dovey H., Davis D., Sinha S., Schlossmacher M., Whaley J., Swindlehurst C., McCormack R., Wolfert R., Selkoe D., Lieberburg I. and Schenk D. (1992) Isolation and quantification of soluble Alzheimer's beta-peptide from biological fluids. Nature 359, 325-327.

40. Shivers B. D., Hilbich C., Multhaup G., Salbaum M., Beyreuther K. and Seeburg P. H. (1988) Alzheimer's disease amyloidogenic glycoprotein: Expression pattern in rat brain suggests a role in cell contact. Eur. molec. Biol. Org. J. 7, 1365-1370.

41. Shi G.-P., Munger J. S., Meara J. P., Rich D. H. and Chapman H. A. (1992) Molecular cloning and expression of human alveolar macrophage cathepsin $\mathrm{S}$, an elastinulytic cysteine protease. J. biol. Chem. 267, 7258-7262.

42. Shoji M., Golde T. E., Ghiso J., Cheung T. T., Estus S., Shaffer L. M., Cai X.-D., McKay D. M., Tinter R., Frangione B. and Younkin S. G. (1992) Production of the Alzheimer amyloid $\beta$ protein by normal proteolytic processing. Science 258, 126-129.

43. Sisodia S. S., Koo E. H., Beyreuther K., Unterbeck A. and Price D. L. (1990) Evidence that $\beta$-amyloid protein in Alzheimer's disease is not derived by normal processing. Science $248,492-495$.

44. Tryggvason K., Hoyhtya M. and Salo T. (1987) Proteolytic degradation of extracellular matrix in tumor invasion. Biochim. biophys. Acta. 907, 191-217.

45. Uchiyama Y., Watanabe T., Watanabe M., Ishii Y., Matsuba H., Waguri S. and Kominami E. (1989) Immunocytochemical localization of cathepsins B, H, L and T4 in follicular cells of rat thyroid gland. J. Histochem. Cytochem. 37,
$691-696$.

46. Uchiyama Y., Nakajima M., Muno D., Watanabe T., Ishii Y., Waguri S., Sato N. and Kominami E. (1990) Immunocytochemical localization of cathepsins B and $\mathbf{H}$ in corticotrophs and melanotrophs of rat pituitary gland. J. Histochem. Cytochem. 38, 633-639. 
47. Warfel A. H., Zucker-Franklin D., Frangione B. and Ghiso J. (1987) Constitutive secretion of cystatin C (gamma-trace) by monocytes and macrophages and its down regulation after stimulation. Fedn. Eur. biochem. Socs. Lett. 166, 1912-1917.

48. Watanabe T., Watanabe M., Ishii Y., Kimura S., Fujita T., Kominami E., Katunuma N. and Uchiyama Y. (1989) An immunohistochemical study on co-localization of cathepsin $B$ and atrial natriuretic peptides in secretory granules of atrial myoendocrine cells of rat heart. J. Histochem. Cytochem. 37, 347--351.

49. Watson S. J., Sherman S. J., Kelsey J. E., Burke S. and Akil II. (1987) In Situ Hybridization, pp. 126-145. Oxford University Press, New York.

50. Wiederanders B., Bromme D., Kirschke H., von Figura K., Schmidt B. and Peters C. (1992) Phylogenetic conservation of cysteine proteinases. Cloning and expression of a cDNA for human cathepsin S. J. hiol. Chem. 267, 13,708-13,713.

(Accepted 5 October 1993) 